\title{
A Simple and Sensitive HPTLC Method for Simultaneous Determination of Metformin Hydrochloride and Sitagliptin Phosphate in Tablet Dosage Form
}

\author{
Darshana K. Modi, Punit B. Parejiya, and Bhavesh H. Patel \\ Department of Pharmaceutical Chemistry, K. B. Institute of Pharmaceutical Education and Research, Kadi Sarva Vishwavidyalaya, \\ Gujarat, Gandhinagar 382023, India \\ Correspondence should be addressed to Darshana K. Modi; darshanapharma@gmail.com
}

Received 25 June 2012; Revised 17 September 2012; Accepted 20 September 2012

Academic Editor: Paraskevas D. Tzanavaras

Copyright (C) 2013 Darshana K. Modi et al. This is an open access article distributed under the Creative Commons Attribution License, which permits unrestricted use, distribution, and reproduction in any medium, provided the original work is properly cited.

\begin{abstract}
A simple, rapid, and precise high-performance thin-layer chromatographic (HPTLC) method for simultaneous estimation of two antidiabetic drugs, metformin hydrochloride and sitagliptin phosphate, in tablet dosage form has been developed and validated. Chromatography was performed on silica gel $60 \mathrm{~F}_{254}$ plates with butanol : water : glacial acetic acid $(6: 2: 2$, v/v/v) as mobile phase. This system gave a good resolution for metformin hydrochloride $\left(R_{f}\right.$ value of $\left.0.35 \pm 0.01\right)$ and sitagliptin phosphate $\left(R_{f}\right.$ value of $0.75 \pm 0.01)$. Detection and quantification were carried out at $227 \mathrm{~nm}$. The linear regression data for the calibration plot showed a good relationship with $r=0.9995$ and 0.9991 for metformin hydrochloride and sitagliptin phosphate, respectively. The method was validated for precision and recovery. The limits of detection and quantification were 13.05 and $39.56 \mathrm{ng} / \mu \mathrm{L}$ for metformin hydrochloride and 2.65 and $8.03 \mathrm{ng} / \mu \mathrm{L}$ for sitagliptin phosphate, respectively. The amounts of the drugs in the marketed formulation were $99.86 \%$ and $98.91 \%$ for metformin hydrochloride and sitagliptin phosphate, respectively.
\end{abstract}

\section{Introduction}

Metformin hydrochloride (MET), N, N-dimethylimidodicarbonimidic diamide monohydrochloride (Figure 1(a)), is an antihyperglycemic agent that improves glucose tolerance in patient with type II diabetes, lowering both basal and postprandial plasma glucose. Metformin hydrochloride decreases hepatic glucose production, decreases intestinal absorption of glucose, and improves insulin sensitivity by increasing peripheral glucose uptake and utilization [1]. Sitagliptin phosphate (SITA), (3R)-3-amino-1-[3(trifluoromethyl)-6,8-dihydro-5 h- $[1,2,4]$ triazolo $[3,4-$ c]pyrazin-7-yl]-4-(2,4,5-trifluorophenyl)butan-1-one (Figure 1(b)), is new oral antidiabetic agent that blocks dipeptidyl peptidase-4 (DPP-4) activity. SITA increased incretin levels (GLP-1 and GIP) which inhibit glucagon release, in turn decreases blood glucose, but more significantly increases insulin secretion; this suppresses the release of glucagon from the pancreas and drives down blood sugar levels [2].

A literature survey revealed that MET is official in IP [4], BP [3], and USPNF [5], while SITA is not yet official in any of the pharmacopoeia. A detailed literature survey found that LC-MS/MS method has been reported for quantitation of MET and SITA from mouse and human dried blood spots [6]. UV spectrophotometry has also been used for simultaneous determination of MET and SITA in tablet dosage form [7]. Determination of MET and SITA in tablet dosage form by liquid chromatography has also been reported [8]. To our knowledge, this is the first report of HPTLC method for simultaneous estimation of MET and SITA in a tablet dosage form. The HPTLC method is useful for simultaneous processing of sample and standard, reduced need for internal standard, lower analysis time and less cost per analysis, simple sample preparation, no requirements of prior treatment for solvents like filtration and degassing, no interference from 
<smiles>CN(C)C(=N)NC(=N)N</smiles>

(a)<smiles>N[C@@H](CC(=O)N1CCn2c(nnc2C(F)(F)F)C1)Cc1cc(F)c(F)cc1F</smiles>

(b)

FIgURE 1: Structural formula for MET (a) and SITA (b).

previous analysis, fresh stationary and mobile phases for each analysis with no contamination, the ability for visual detection with an open system, and to determine nonUV absorbing compounds detected by postchromatographic derivatization. It reveals that proposed method require less time and less solvent for the analysis. So proposed method is cost effective as HPLC grade solvents are too costly.

\section{Experimental}

2.1. Materials. Butanol (AR grade) and glacial acetic acid (AR grade) were supplied by SD Fine Chemicals (Mumbai, India). Distilled water was used throughout the study. Reference standard of MET (99.5\%) was procured from Torrent Research Centre (Bhat, Gandhinagar, India). Reference standard of SITA (99.8\%) was procured from MSD Pharmaceuticals Private Limited (Bhiwandi, Maharashtra, India). JANUMET tablets were purchased from local market.

\subsection{HPTLC Instrumentation. A CAMAG HPTLC system} equipped with Linomat 5 autosampler, TLC scanner 3, and winCATS 1.2.2 software (CAMAG, Muttens, Switzerland) was used. The slit dimension was kept at $5.00 \times 0.45 \mathrm{~mm}$, and $20 \mathrm{~mm} / \mathrm{sec}$ scanning speed was employed. Chromatography was performed on precoated silica gel $60 \mathrm{~F}_{254}$ TLC plates $(10 \times 10 \mathrm{~cm}$, catalogue number 1.05554.007) (Merck, Darmstadt, Germany) using butanol: water: glacial acetic acid $(6: 2: 2, \mathrm{v} / \mathrm{v} / \mathrm{v})$ as mobile phase. The band length $6 \mathrm{~mm}$ and distance between bands $15 \mathrm{~mm}$ were kept constant throughout the study. Numbers of applications on the plates were five for standards and three for test samples. The application speed was $150 \mathrm{~nL} / \mathrm{sec}$. Ascending development to a distance of $85 \mathrm{~mm}$ was performed on $20 \times 10 \mathrm{~cm}$ twin through chamber (CAMAG). Chromatograms were evaluated via peak area after scanning in absorbance mode at $227 \mathrm{~nm}$.

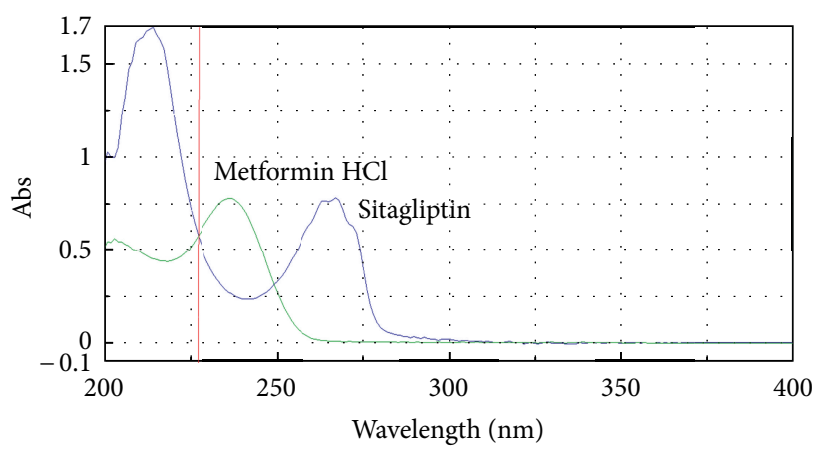

Figure 2: Spectra for MET $(10 \mu \mathrm{g} / \mathrm{mL})$ and SITA $(10 \mu \mathrm{g} / \mathrm{mL})$ wavelength optimization.

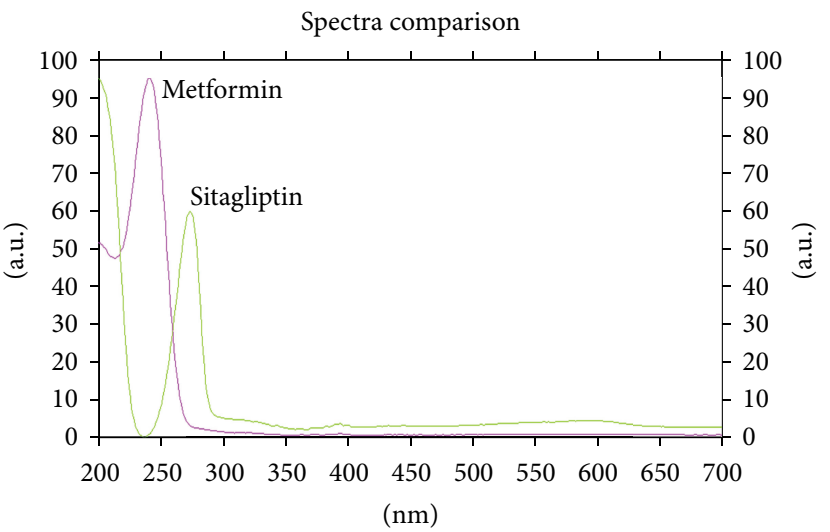

FIGURE 3: Typical absorption spectra obtained from MET and SITA drug solutions.

2.3. Preparation of Standard Solution. MET $(100 \mathrm{mg})$ and SITA $(10 \mathrm{mg})$ reference substances were accurately weighed and transferred to a $25 \mathrm{~mL}$ volumetric flask. The powder was dissolved in and diluted to volume with methanol to furnish concentrations of $4000 \mu \mathrm{g} / \mathrm{mL}$ MET and $400 \mu \mathrm{g} / \mathrm{mL}$ SITA. This solution $(2.5 \mathrm{~mL})$ was diluted to $10 \mathrm{~mL}$ with methanol to obtain a standard solution having a concentration of MET $(1000 \mathrm{ng} / \mu \mathrm{L})$ and SITA $(100 \mathrm{ng} / \mu \mathrm{L})$.

2.4. Preparation of Sample Solution. Twenty tablets were weighed and ground to a fine powder. A quantity of powder equivalent to $200 \mathrm{mg}$ MET and $20 \mathrm{mg}$ SITA was weighed and transferred to a $50 \mathrm{~mL}$ volumetric flask. The powder was dissolved in methanol, sonicated for $30 \mathrm{~min}$, diluted to volume upto mark to furnish a solution containing $4000 \mu \mathrm{g} / \mathrm{mL}$ MET and $400 \mu \mathrm{g} / \mathrm{mL}$ SITA. The solution was filtered through Whatman filter paper number 41 . Then $2.5 \mathrm{~mL}$ of the solution was diluted to $10 \mathrm{~mL}$ with methanol to furnish a solution containing $1000 \mathrm{ng} / \mu \mathrm{L}$ MET and $100 \mathrm{ng} / \mu \mathrm{L}$ SITA.

2.5. Method Validation. Validation was done with respect to various parameters required under ICH guideline Q2 (R1) [9]. 


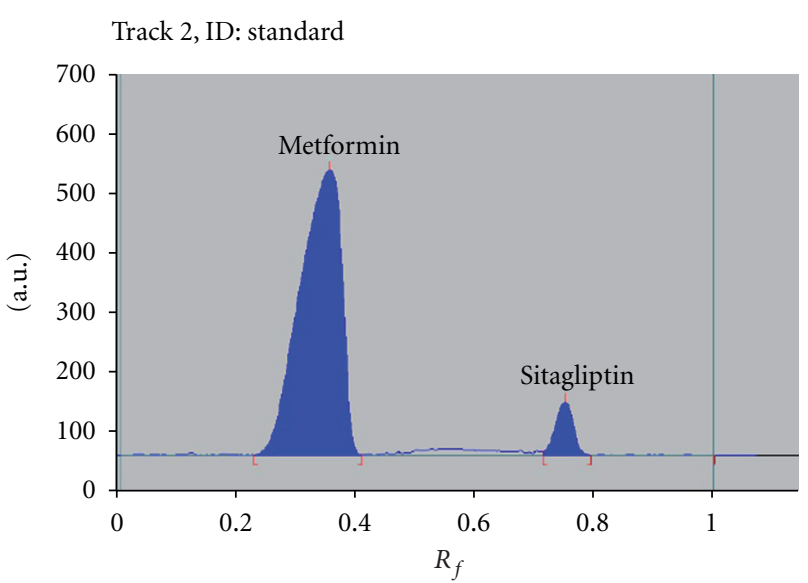

(a)

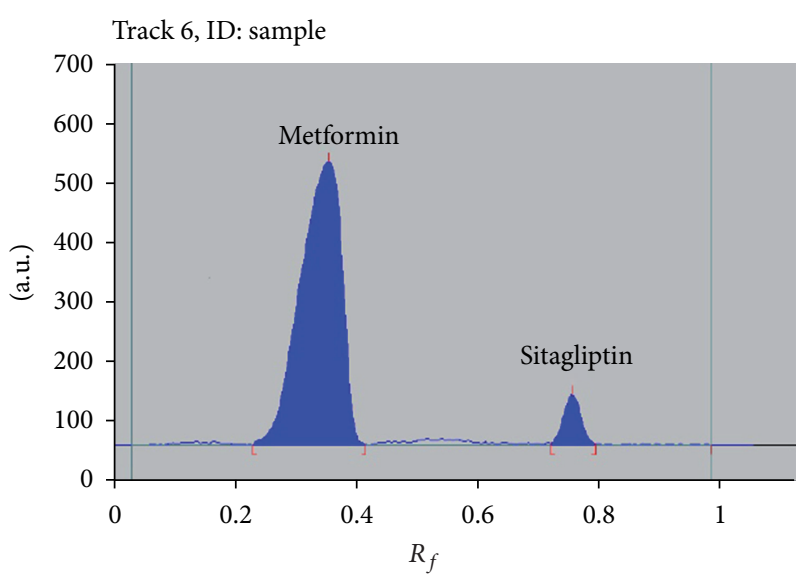

(b)

FIGURE 4: Chromatogram for standards of MET ( $6 \mu \mathrm{g} / \mathrm{band})$ and SITA $(0.6 \mu \mathrm{g} / \mathrm{band})$ (a) and JANUMET tablet (b).

TABLE 1: Statistical evaluation of linear part of calibration dependence of MET and SITA.

\begin{tabular}{lcc}
\hline Parameter & MET & SITA \\
\hline Range (ng/band) & $500-10000$ & $50-1000$ \\
Slope & 3.3592 & 2.5678 \\
Intercept & +6273 & +453 \\
$r$ & 0.9995 & 0.9991 \\
\hline
\end{tabular}

2.5.1. Linearity. Calibration curve was plotted over a concentration range from 500 to $10000 \mathrm{ng} /$ band for MET and 50 to $1000 \mathrm{ng} / \mathrm{band}$ for SITA. For the calibration curves, standard solutions of MET and SITA $(0.5,2.0,4.0,6.0,8.0$, and $10.0 \mu \mathrm{L})$ were applied to the plate. The plate was developed in a developing chamber previously saturated with the mobile phase for 15 minutes. Each reading was the average of three determinations.

2.5.2. Accuracy (Percent of Recovery). The accuracy of the method was determined by calculating recoveries of MET and SITA by the standard addition method. The analyzed samples (3000 ng/band and $300 \mathrm{ng} / \mathrm{band})$ were spiked with extra concentration levels of 1000,3000, and $5000 \mathrm{ng} / \mathrm{band}$ for MET and 100, 300, and $500 \mathrm{ng} / \mathrm{band}$ for SITA, and the mixtures were reanalyzed by the proposed method. Recovery analyses were repeated three times for each level of all samples.

2.5.3. Precision. The precision of developed method was checked by repeatedly $(n=6)$ injecting $6000 \mathrm{ng} /$ band sample solution of MET and $600 \mathrm{ng} / \mathrm{band}$ sample solution of SITA, without changing the position of plate for HPTLC method. Repeatability of a sample application and measurement of the peak area were determined on the same day by the repeated application $(n=6)$ of sample solutions, while intermediate precision was evaluated by comparing the assays for three different days.

2.5.4. Limit of Detection and Limit of Quantification. The limit of detection (LOD) and limit of quantification (LOQ) were calculated using the equations $\mathrm{LOD}=3.3 \times \mathrm{N} / \mathrm{B}$ and LOQ $=10 \times N / B$, where $N$ is standard deviation of the peak area $(n=3)$, taken as measure of the noise, and $B$ is the slope of the corresponding calibration curve.

2.5.5. Selectivity. Selectivity of the method was tested by comparison of peaks of test compounds with those of standards prepared as mentioned before.

2.6. Procedure for Assay. Twenty tablets were weighed and powdered, and an amount of tablet powder equivalent to $200 \mathrm{mg}$ of MET and $20 \mathrm{mg}$ of SITA was taken in a $50 \mathrm{~mL}$ volumetric flask, sonicated for $30 \mathrm{~min}$, and diluted to the mark with methanol. The solution was filtered through Whatman paper number 41 . Then $2.5 \mathrm{~mL}$ of the solution was diluted to $10 \mathrm{~mL}$ with methanol. $6 \mu \mathrm{L}$ of this filtrate was applied to the HPTLC plate and developed, dried, and scanned. Quantity analysis of MET and SITA was made on the basis of peak areas received for standard solutions.

\section{Results and Discussion}

3.1. Wavelength Optimization. UV-vis spectra (Figure 2) of MET and SITA were measured from 200 to $400 \mathrm{~nm}$ and $227 \mathrm{~nm}$ was used as the optimum wavelength throughout the experiment for both substances.

\subsection{Method Validation}

3.2.1. Linearity. The calibration curve was linear from 500 to $10000 \mathrm{ng} / \mathrm{band}$ for MET and from 50 to $1000 \mathrm{ng} / \mathrm{band}$ for SITA, respectively. Statistical evaluations of the linear part of calibration dependence of MET and SITA are presented in Table 1.

3.2.2. Accuracy (Percent of Recovery). The analyzed samples were spiked with extra concentration levels of 1000, 3000, and $5000 \mathrm{ng} / \mathrm{band}$ for MET and 100, 300, and $500 \mathrm{ng} / \mathrm{band}$ 
TABLE 2: The recovery studies of MET and SITA.

\begin{tabular}{lccc}
\hline Compound & $\begin{array}{c}\text { Amount taken } \\
(\mathrm{ng})\end{array}$ & $\begin{array}{c}\text { Amount added } \\
(\mathrm{ng})\end{array}$ & $\begin{array}{c}\text { Recovery (\%) } \pm \text { RSD (\%) } \\
(n=3)\end{array}$ \\
\hline \multirow{3}{*}{ MET } & 3000 & 1000 & $99.39 \pm 1.10$ \\
& 3000 & 3000 & $101.64 \pm 1.01$ \\
\hline \multirow{3}{*}{ SITA } & 3000 & 5000 & $98.14 \pm 1.06$ \\
& 300 & 100 & $100.57 \pm 0.73$ \\
& 300 & 300 & $99.29 \pm 1.08$ \\
\hline
\end{tabular}

TABLE 3: Data indicating various validation parameters of HPTLC method $(n=6)$.

\begin{tabular}{lcc}
\hline & MET & SITA \\
\hline Precision $(n=6)$ & & \\
Mean \pm SD; RSD $(\%)$ & & \\
Method precision & $99.86 \pm 0.88 ; 0.88$ & $98.91 \pm 1.21 ; 1.23$ \\
Intraday precision & $100.43 \pm 0.49 ; 0.49$ & $99.12 \pm 0.71 ; 0.72$ \\
Interday precision & $100.46 \pm 1.14 ; 1.13$ & $100.56 \pm 1.43 ; 1.43$ \\
LOD $(\mathrm{ng} / \mu \mathrm{L})$ & 13.05 & 2.65 \\
LOQ $(\mathrm{ng} / \mu \mathrm{L})$ & 39.56 & 8.03 \\
\hline
\end{tabular}

for SITA, and the mixtures were reanalyzed by the proposed method. Recovery analyses were repeated three times for each level of all samples. The results are presented in Table 2.

3.2.3. Precision. The precision of the developed method was expressed as a percentage of relative standard deviation (percent of RSD) for repeatability (intraday precision) and intermediate precision (interday precision). The data obtained were within $2 \%$ RSD (Table 3 ).

3.2.4. Limit of Detection and Limit of Quantification. The LOD and LOQ values were 13.05 and $39.56 \mathrm{ng} / \mu \mathrm{L}$ for MET and 2.65 and $8.03 \mathrm{ng} / \mu \mathrm{L}$ for SITA, respectively (Table 3). The data shows that the method is sensitive for the determination of MET and SITA.

3.2.5. Selectivity. Typical absorption spectra of MET and SITA are shown in Figure 3. Selectivity of the method was tested by comparison of peaks of test compounds with those of standards prepared as mentioned before. Related chromatogram is presented in Figure 3. Thus it can be concluded that the excipients did not interfere with the peaks from standard drug solutions.

3.3. Application of the Validated Method to a Pharmaceutical Preparation. The proposed validated method was successfully applied to determine MET and SITA in their combined dosage form. The label claim was $500 \mathrm{mg}$ of MET and $15 \mathrm{mg}$ of SITA per tablet. The percent of assay of MET and SITA found in JANUMET tablets by the proposed method is $99.86 \%$ and $98.91 \%$, with percent of RSD $0.88 \%$ and $1.23 \%$, respectively (Figure 4 ).

\section{Conclusion}

A new HPTLC method for simultaneous determination of MET and SITA in pharmaceutical tablet formulation has been developed. The method was found to be simple, sensitive, precise, accurate, and specific for quantification of MET and SITA in pharmaceutical formulation. It does not suffer from interference from common excipients present in the pharmaceutical preparation and can be conveniently adopted for quality-control analysis.

\section{References}

[1] Martinfdale-the Complete Drug Reference, Pharmaceutical Press, London, UK, 2005.

[2] G. A. Herman, A. Bergman, F. Liu et al., "Pharmacokinetics and pharmacodynamic effects of the oral DPP-4 inhibitor sitagliptin in middle-aged obese subjects," Journal of Clinical Pharmacology, vol. 46, no. 8, pp. 876-886, 2006.

[3] British Pharmacopoeia, vol. 1 of Controller of Her Majesty's Stationary Office, London, UK, 4th edition, 2008.

[4] Indian Pharmacopoeia, vol. 1, The Controller of Publications, New Delhi, India, 1996.

[5] United State Pharmacopoeia National Formulary, vol. 2, United States Pharmacopoeial Convention, Rockville, Md, USA, 2005.

[6] J. G. Swales, R. T. Gallagher, M. Denn, and R. M. Peter, "Simultaneous quantitation of metformin and sitagliptin from mouse and human dried blood spots using laser diode thermal desorption tandem mass spectrometry," Journal of Pharmaceutical and Biomedical Analysis, vol. 55, no. 3, pp. 544-551, 2011.

[7] G. Khan, D. Sahu, Y. P. Agrawal, N. Sabarwal, A. Jain, and A. K. Gupta, "Simultaneous estimation of metformin and sitagliptin in tablet dosage form," Asian Journal of Biochemical and Pharmaceutical Research, vol. 1, pp. 352-358, 2011.

[8] R. I. El-Bagary, E. F. Elkady, and B. M. Ayoub, "Liquid chromatographic determination of sitagliptin either alone or in ternary mixture with metformin and sitagliptin degradation product," Talanta, vol. 85, no. 1, pp. 673-680, 2011.

[9] ICH Harmonized Tripartite Guidelines on Validation of Analytical Procedures: Text and Methodology Q2 (R1), Current Step 4 Version, Geneva, Switzerland, 2005. 

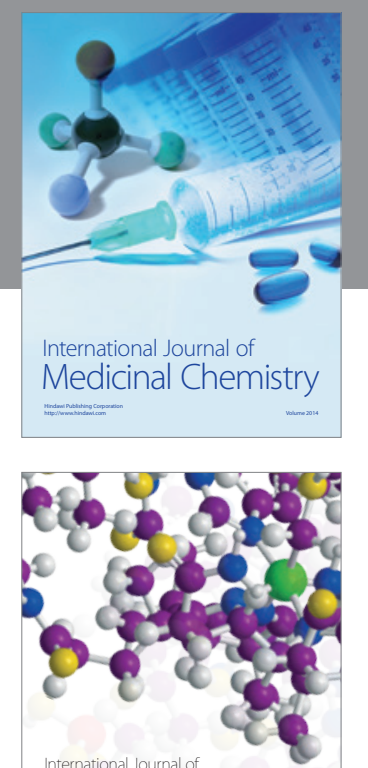

\section{Carbohydrate} Chemistry

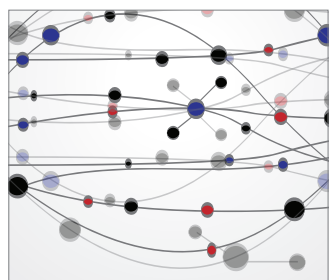

The Scientific World Journal
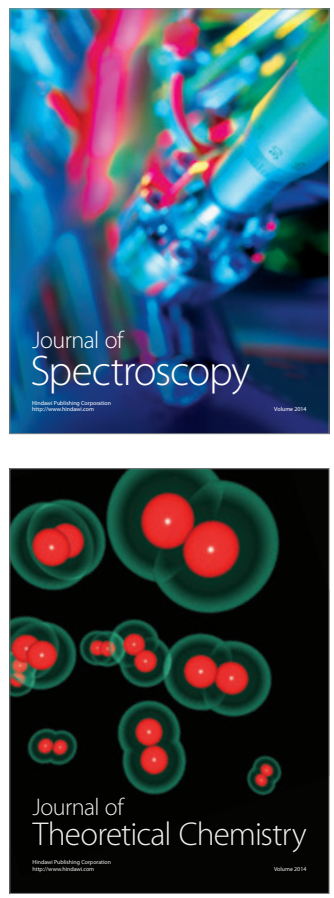
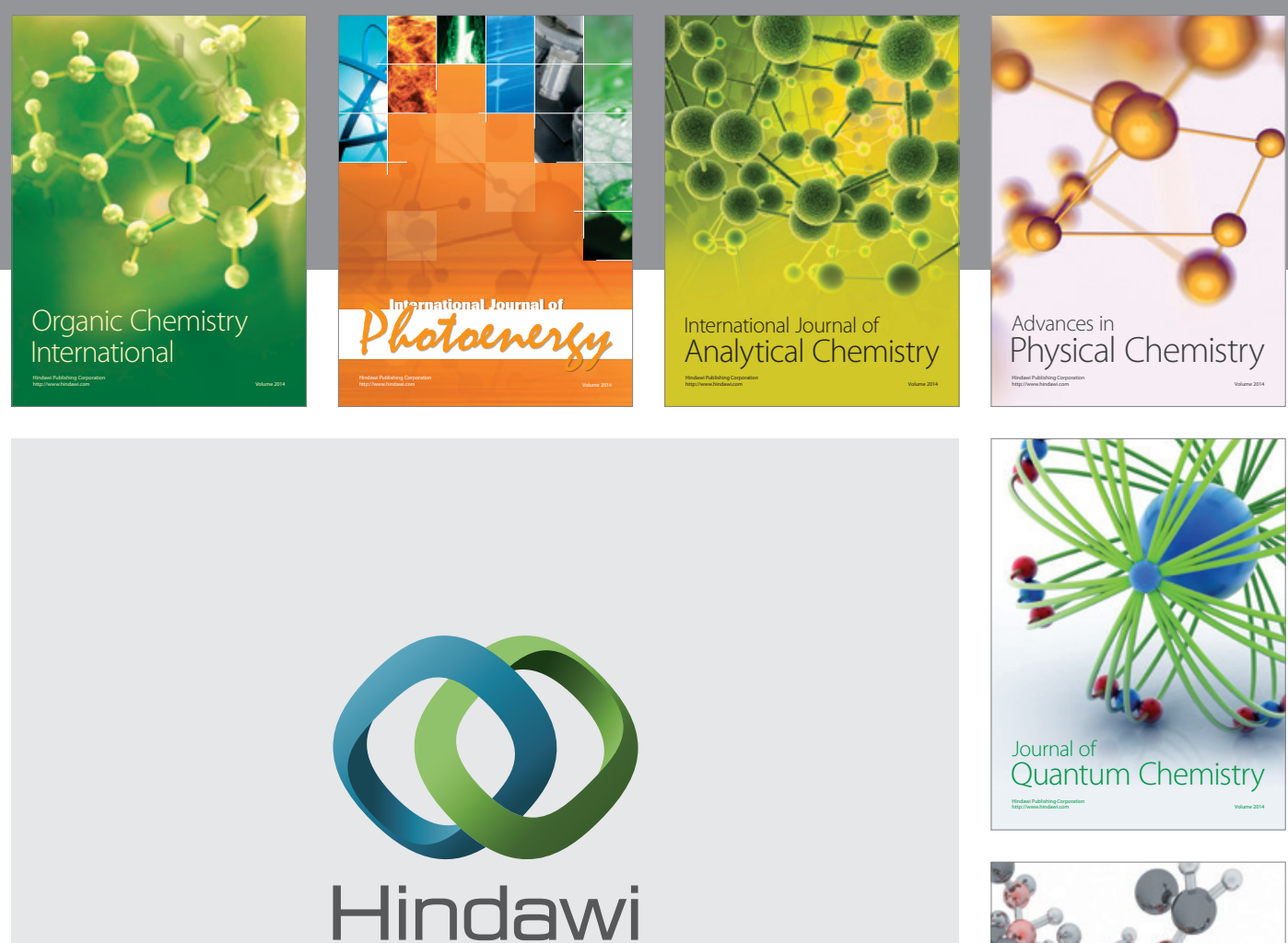

Submit your manuscripts at

http://www.hindawi.com

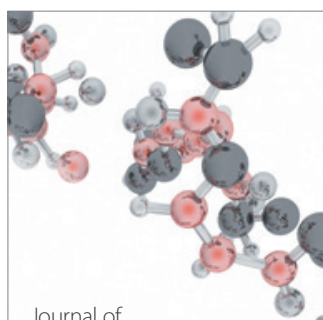

Analytical Methods

in Chemistry

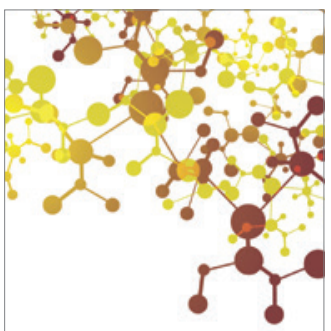

Journal of

Applied Chemistry

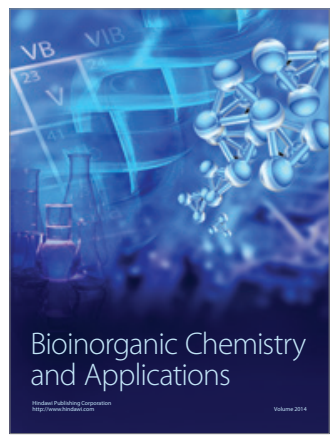

Inorganic Chemistry
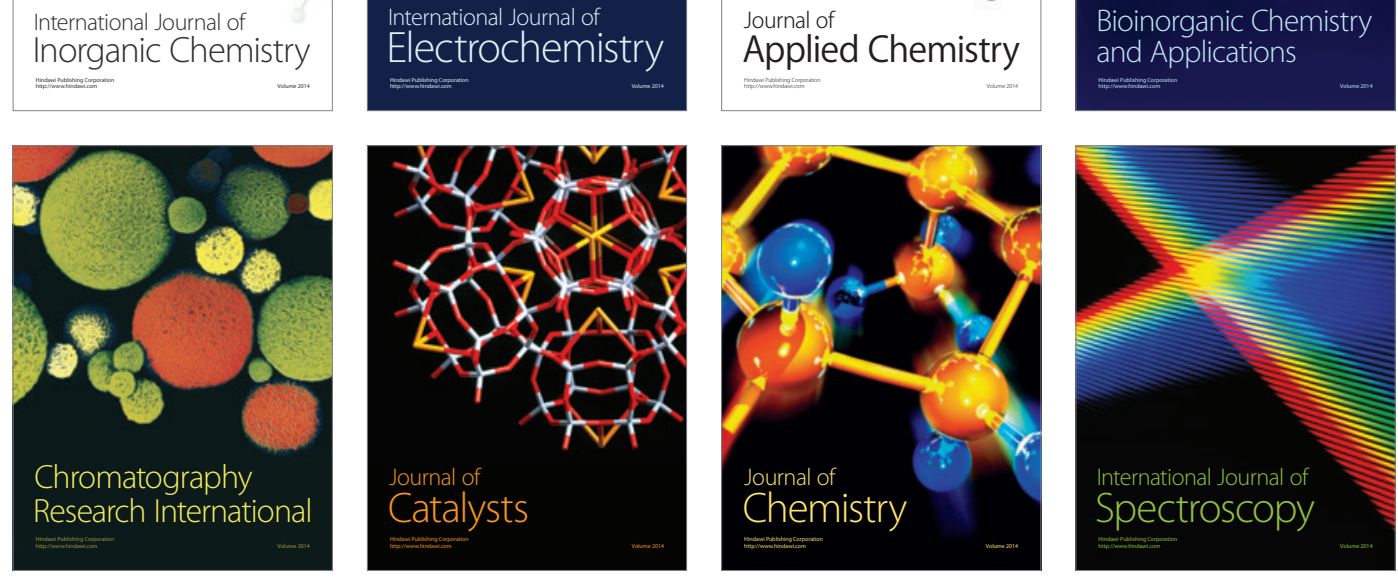